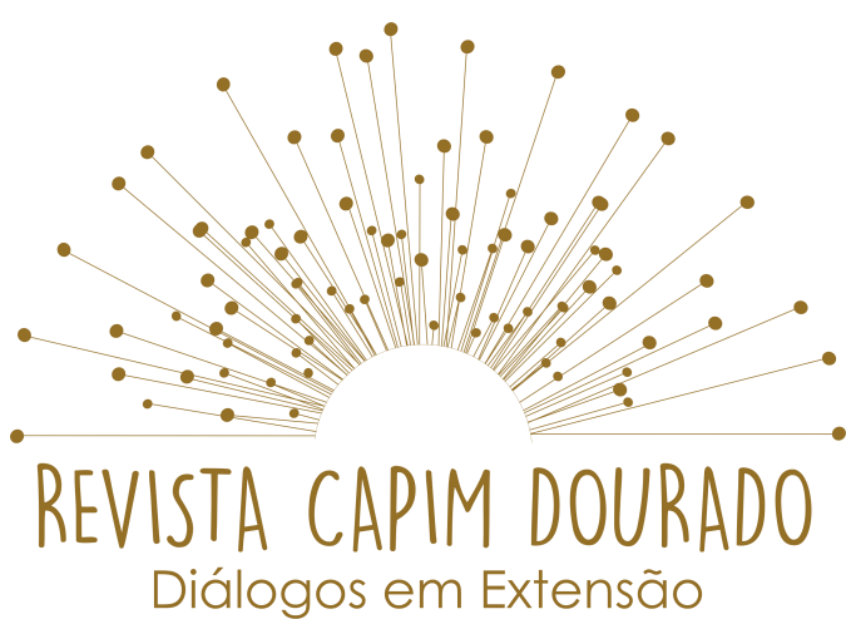

\title{
A EXTENSÃO UNIVERSITÁRIA EM TEMPOS DE PANDEMIA: a PROEX/UFT no enfrentamento da Covid- 19
}

UNIVERSITY EXTENSION IN PANDEMIC TIMES: PROEX / UFT in the fight against Covid-19

\section{EXTENSIÓN UNIVERSITARIA EN TIEMPOS DE PANDEMIA: PROEX / UFT en la lucha contra Covid-19}

\section{Josivânia Sousa Costa Ribeiro' Maria Santana Ferreira dos Santos Milhomem²}

\begin{abstract}
RESUMO
O presente relato de experiência visa apresentar a extensão universitária integrada ao contexto contemporâneo e a gestão da Pró-Reitoria de Extensão, Cultura e Assuntos Comunitários-PROEX/UFT no enfrentamento da Covid-19. A extensão universitária integrada ao ensino e à pesquisa propicia a promoção de ações que articulem à interação transformadora entre universidade e sociedade corroborando com os apelos da comunidade que tanto espera da universidade, principalmente em tempos difíceis, como a pandemia.
\end{abstract}

PALAVRAS-CHAVE: Extensão universitária; pandemia; covid-19.

\section{ABSTRACT}

The present experience report aims to present the university extension integrated to the contemporary context and the management of the Dean of Extension,

\footnotetext{
1 Pedagoga e Mestra em Educação pela Universidade Federal do Tocantins-UFT. E-mail: josivaniascr@uft.edu.br

2 Doutorado em Educação (Conceito CAPES 5) Universidade de Brasília, UnB, Brasil. E-mail: msfsantos@mail.uft.edu.br

josivaniascr@uft.edu.br. Revista Capim Dourado: Diálogos em Extensão, Palmas, v. 3, n. 2, p. 41-50, mai-ago. 2020
} 


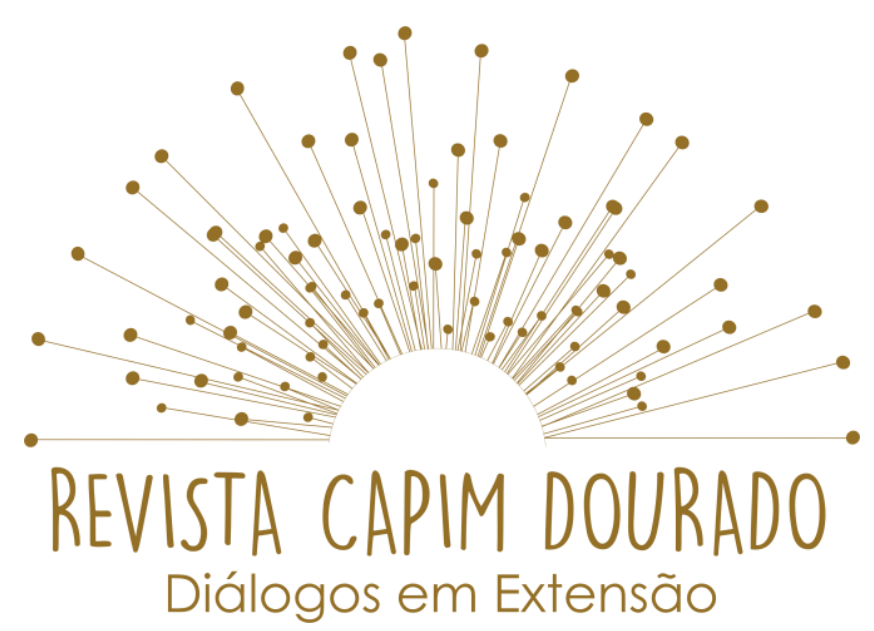

Culture and Community Affairs-PROEX / UFT when facing Covid-19. The university extension integrated to teaching and research provides the promotion of actions that articulate the transformative interaction between university and society, corroborating the community's appeals that so much awaits from the university, especially in difficult times, such as the pandemic.

KEYWORDS: University Extension; pandemic; Covid-19.

\section{RESUMEN}

El presente informe de experiencia tiene como objetivo presentar la extensión universitaria integrada al contexto contemporáneo y la gestión del Decano de Extensión, Cultura y Asuntos Comunitarios-PROEX / UFT cuando se enfrenta a Covid-19. La extensión universitaria integrada a la enseñanza y la investigación proporciona la promoción de acciones que articulan la interacción transformadora entre la universidad y la sociedad, corroborando los atractivos de la comunidad que tanto se esperan de la universidad, especialmente en tiempos difíciles, como la pandemia.

PALABRAS CLAVE: Extensión Universitaria; pandemia; Covid-19.

\section{A Extensão Universitária Integrada ao Contexto Social Contemporâneo}

A Política Nacional de Extensão universitária, elaborada em 2012, no Fórum de Pró-Reitores de Extensão das Instituições de Educação Superiores Públicas Brasileiras (FORPROEX) define o conceito de extensão universitária:

A Extensão Universitária, sob o princípio constitucional da indissociabilidade entre o ensino, pesquisa e extensão, é um processo interdisciplinar, educativo, cultural, científico e político que promove a interação transformadora entre a Universidade e outros setores da sociedade (FORPROEX, 2012, p. 15). 


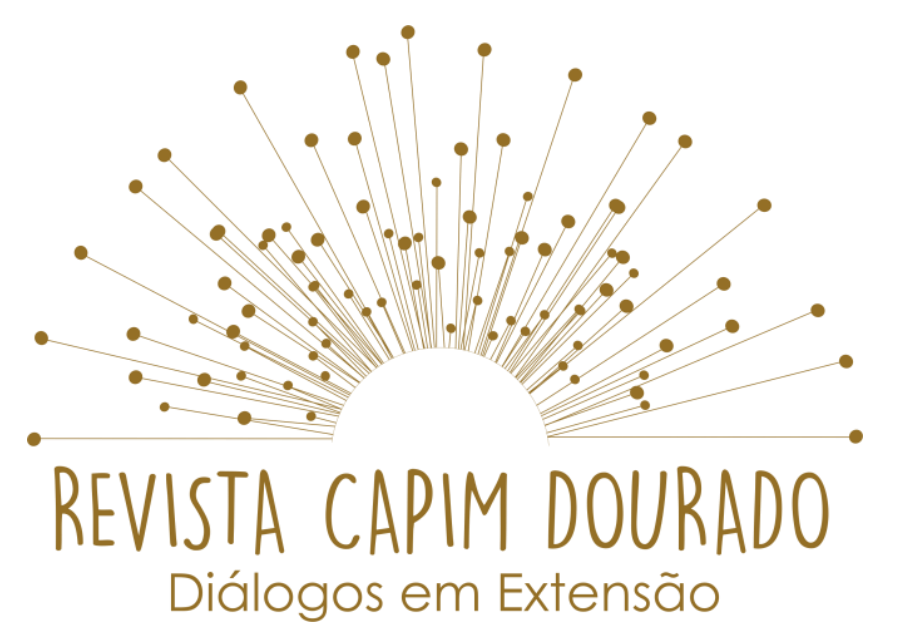

Diante do conceito epistemológico da extensão universitária é possível identificar e reconhecer a importância do entrelaçamento entre a universidade e a sociedade a partir do processo interdisciplinar, educativo, cultural, científico e político que se destina na promoção de ações que visem à interação transformadora entre universidade e sociedade.

Para a efetivação de uma ação de extensão é necessário ater-se às diretrizes que objetivam orientar desde a sua concepção à avaliação dos resultados propostos. As diretrizes são as seguintes: Interação Dialógica, Interdisciplinaridade e Interprofissionalidade, Indissociabilidade EnsinoPesquisa-Extensão, Impacto na Formação do Estudante e Impacto e Transformação Social.

As diretrizes norteiam as ações de extensão que perpassam pela interação primordial entre a universidade e sociedade, relações marcadas pelos diálogos, trocas de saberes, escuta sensível das comunidades e a partir destas interações possam produzir um novo conhecimento. Assim, contribuem para a consolidação de uma sociedade mais justa, democrática e acima de tudo mais humana e solidária.

É preciso salientar que vivemos em sociedade em que os acontecimentos são efêmeros em virtude da realidade complexa que exige de nós uma visão mais contextualizada e integral. Neste sentido, as ações de extensão deverão ser pautadas na interdisciplinaridade que se propõe a união de saberes disciplinares, das áreas de conhecimento da extensão. Ressalta-se que estas ações poderão ser desenvolvidas com diálogo entre os profissionais e intersetoriais que acrescentarão ao debate novos olhares frente às demandas sociais. 


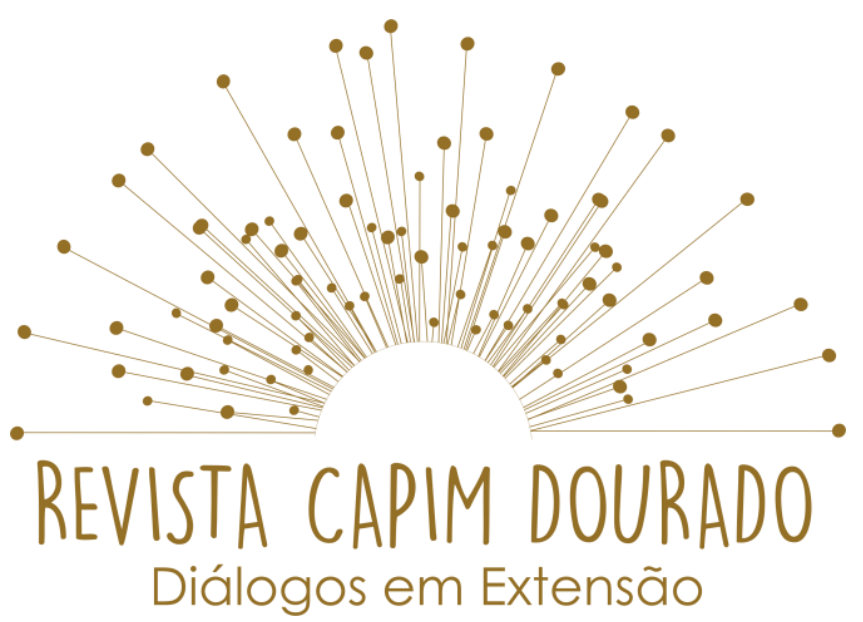

A indissociabilidade Ensino, Pesquisa e Extensão, princípio constitucional, reafirma a extensão como processo acadêmico, que integra os pilares da universidade. Destaca-se que a extensão é a ponte capaz de aproximar os conhecimentos produzidos pelo ensino e a produção das pesquisas à sociedade e retroalimentá-las num processo via de mão dupla.

Diante o exposto, a extensão universitária tem como propósito oportunizar espaços de diálogos extramuros que possibilitem a formação integral dos estudantes e juntos - público interno e externo - possam corroborar com os desafios e demandas da sociedade que são cada vez mais desafiadores e complexos.

\section{A Gestão da PROEX/UFT no enfrentamento da Covid-19}

A Pró-Reitoria de Extensão, Cultura e Assuntos Comunitários-PROEX da Universidade Federal do Tocantins, em seu processo de gestão, realiza-se anualmente uma imersão (capacitação) com a equipe de servidores que integram a Pró-Reitoria, para discutir as ações que serão realizadas ao longo do ano, editais a ser lançados, rever os pontos positivos e negativos das ações passadas, ou seja, refletir, avaliar e planejar as ações de extensão da universidade.

Há um planejamento traçado a ser efetivado e agora estamos vivendo um momento novo, desconhecido, inesperado, que traz consigo as 'incertezas' Morin (1990). E agora, como reagir diante destas incertezas? Estamos vivendo uma pandemia que assola o planeta, decorrente do Coronavírus - Covid-19, uma doença viral em que é necessário o distanciamento e isolamento social como medida de proteção e transmissibilidade. 


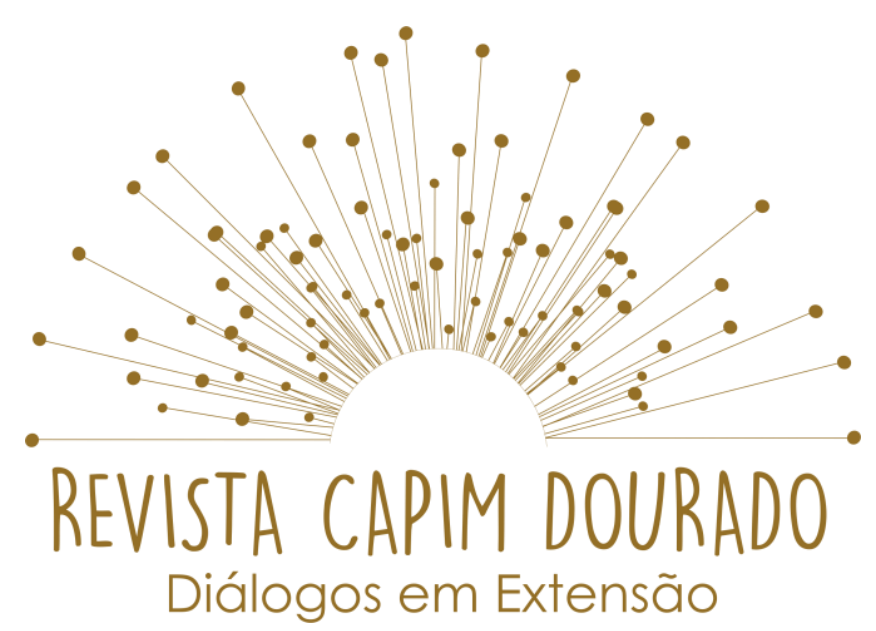

Como pensar a extensão universitária em tempos de pandemia, tendo em vista as ações de extensão ser de contato físico com grupos e territórios? Estagnar, ou reagir?

Neste sentido, a PROEX/UFT, em diálogo com o comitê de crise, o grupo gestor da universidade, docentes e comunidade acadêmica e de acordo com a Resolução Consuni no ${ }^{\circ} 3^{3}$, de 30 de março de 2020 , as atividades de extensão ${ }^{4}$ a serem realizadas em formato presencial fossem suspensas até que normalize as atividades do calendário da universidade e que sejam liberadas as medidas de segurança em relação ao Covid-19.

Entretanto, diante da crise sanitária que estamos atravessando surgiram outras demandas que foram realizadas e apoiadas pela Pró-Reitoria de Extensão que tem a missão de acolher e orientar estas ações que visam contribuir significativamente com a sociedade, principalmente com as minorias e as comunidades em situação de vulnerabilidade social.

Apresentaremos a seguir algumas ações que foram inseridas pela gestão da Proex/UFT para o enfrentamento ${ }^{5}$ da Covid-19.

Visando apresentar e comunicar as ações realizadas pela Instituição nesse período a todo o território Nacional, e especificamente ao estado do Tocantins, criamos um Painel integrado no sítio da UFT, onde são atualizados diariamente e mostra as ações, público atingido, valor investido, parcerias e produtos gerados.

\footnotetext{
${ }^{3}$ Trata do Plano de Contingência para desenvolver atividades administrativas e acadêmicas da UFT, tendo em vista as medidas de proteção para o enfrentamento da emergência de saúde pública de importância internacional, decorrente do Coronavírus- COVID-19.

${ }^{4}$ (eventos, cursos, projetos, programas e prestação de serviços)

5 Painel Integrado de Ações contra a Covid-19, encontram-se ações apoiadas pela Proex/UFT para o enfrentamento da Covid-19.

josivaniascr@uft.edu.br. Revista Capim Dourado: Diálogos em Extensão, Palmas, v. 3, n. 2, p. 41-50, mai-ago. 2020
} 


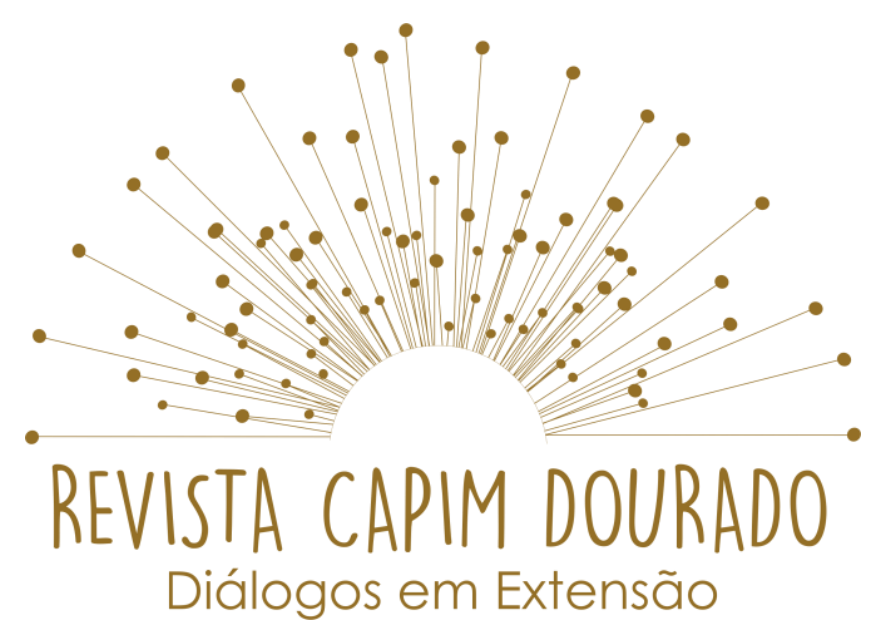

Já são 59 ações de enfrentamento e 32 mil pessoas impactadas diretamente. Essas ações estão direcionadas ao combate a fome, a proteção individual, acompanhamento psicológico em todos os ciclos da vida, realização de exames, compra de equipamentos e insumos, pesquisas científicas, dicas de saúde, assepsia, preventivas, produção de conteúdos, protocolos, vídeos, cartilhas, informativos e assistência aos servidores e estudantes.

Com o intuito de aproximar a comunidade externa e mantê-la conectada à universidade, a Proex/UFT coordena os programas de rádio e rede social: Conexão Proex e Conexão UFT, realizados semanalmente e aborda temas alusivos ao combate à pandemia.

A PROEX é parceira juntamente com os Ministérios do Trabalho e Ministério Público Federal e Curso Graduação em Ciência da Computação no projeto de produção de 10 mil protetores faciais, além de ofertar um edital para bolsas de extensão a estudantes de graduação do Campus de Palmas envolvidos no desenvolvimento do projeto.

Preocupados com a situação econômica da população mais vulnerável do Tocantins, lançamos a "Campanha UFT Solidária" para a arrecadação de alimentos e material de limpeza e foram entregues as famílias em vulnerabilidade socioeconômica, incluindo os estudantes da UFT.

Contudo, essas são algumas das ações que a Pró-Reitoria de Extensão, Cultura e Assuntos Comunitários implantou para o enfrentamento da Covid-19, contribuindo assim, com a missão institucional da universidade em propor ações que visem impactos e transformação social. E, para além dessas ações, a PROEX tem buscado apoiar as ações de extensão coordenadas pelos docentes e/ou técnicos administrativos que são possíveis de continuarem em andamento josivaniascr@uft.edu.br. Revista Capim Dourado: Diálogos em Extensão, Palmas, v. 3, n. 2, p. 41-50, mai-ago. 2020 


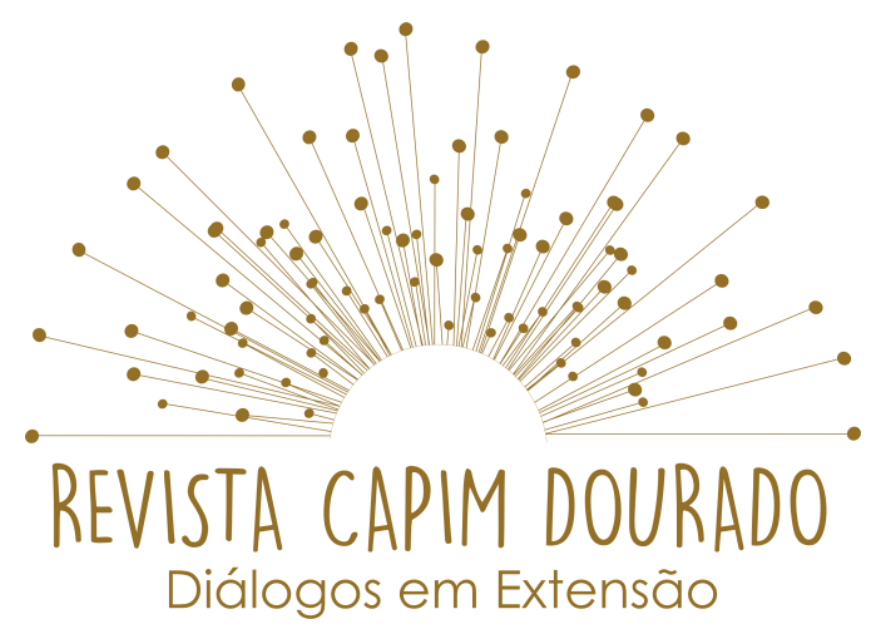

a partir de novas metodologias ou de tecnologias que favoreçam o diálogo entre a universidade e sociedade.

\section{Algumas considerações}

A extensão universitária integrada ao ensino e à pesquisa contribui com a sociedade ao minimizar as demandas sociais que exigem da universidade uma atuação célere e comprometida com os desafios inerentes ao contexto social cada vez mais complexo.

Neste sentido, diante da crise sanitária mundial a qual estamos atravessando urge que a extensão universitária juntamente com outros segmentos da sociedade se unam ao enfrentamento da Covid-19. Contudo, a PROEX/UFT não mediu esforços em apoiar ações com vistas a minimizar os impactos causados pela Covid-19.

Ante o exposto, a extensão universitária deve se fazer presente na sociedade em todos os momentos, principalmente em tempos difíceis, que requer desta uma atuação mais próxima, ética, célere e solidária. Assim, as ações extensionistas podem corroborar com os apelos da comunidade que tanto espera da universidade.

\section{Referências}

FÓRUM DE PRÓ-REITORES DE EXTENSÃO DAS INSTITUIÇÕES PÚBLICAS DE EDUCAÇÃO SUPERIOR BRASILEIRAS. Política Nacional de Extensão Universitária. Gráfica da UFRGS. Porto Alegre, RS, 2012 (Coleção Extensão Universitária; v.7).

MORIN, Edgar. Introdução ao pensamento complexo. Tradução Eliane Lisboa. 5ª edição. Porto Alegre: Sulina, 2015.

josivaniascr@uft.edu.br. Revista Capim Dourado: Diálogos em Extensão, Palmas, v. 3, n. 2, p. 41-50, mai-ago. 2020 